\title{
PENJABARAN STANDAR INTERNASIONAL TRIMS DAN OECD DALAM KETENTUAN HUKUM PENANAMAN MODAL INDONESIA
}

\author{
Oleh: \\ Ni Ketut Supasti Dharmawan', Putu Tuni Caka Bawa Landra², \\ Putu Aras Samsithawrati ${ }^{3}$
}

\begin{abstract}
As a member of the WTO-TRIMs Agreement basically Indonesia has stipulated the National Treatment Principle to the legal provisions relating to investment activities. However, the Indonesian investment Law (Law No. 25 of 2007) still remains that the regulation of National Treatment with regard to national interests. In order to the difficulties may exist in domestic level such as the social, economic as well as values may be different in some member countries, the WTO-TRIMs provide exceptions for the member with notify mandatory requirement to the Board of TRIMs. Relating to investment activities other International standards also relevant to study is the GCG principles developed by the OECD. Although Indonesia is not OECD member countries, the GCG principles adopted in various Indonesian laws related to investment activities doe to it relevant and harmony to the economic, social as well as community values in order to develop capital investment.
\end{abstract}

Key words: International Standards, TRIMS, OECD, GCG, Indonesia Investment Law

\section{PENDAHULUAN}

\subsection{Latar Belakang Masalah}

Perkembangan kegiatan investasi di Indonesia tidak dapat dipungkiri dipengaruhi oleh berbagai faktor, salah satunya adalah faktor penting regulasi hukum yang sangat dibutuhkan oleh para investor. Berdasarkan kajian Duncan H. Meldrum (1994) dikemukakan sekurang-kurangnya ada 7 faktor yang penting dalam kegiatan investasi yaitu: kemudahan mendirikan usaha, tidak ada diskriminasi bagi investor asing, perlakuan yang sama bagi investor asing dan lokal, transparansi dalam perizinan, kebijakan imigrasi, mekanisme penyampaian keluhan kepada pemerintah, serta pemerintah yang

Dosen Progaram Magister (S2) Imu Hukum UNUD. Email: arasswk@yahoo.com

2 Dosen Progaram Magister (S2) Imu Hukum UNUD.

3 Dosen Fakultas Hukum UNUD. responsive terhadap keluhan-keluhan yang diajukan. $^{4}$

Hasil studi Duncan H. Meldrum tersebut di atas ternyata relevan dengan prinsipprinsip transparansi yang merupakan salah satu prinsip GCG (Good Corporate Governance) dan prinsip perlakuan yang sama (non discrimination) yang menjadi salah satu pilar utama legal basis WTO (World Trade Organization). Ketentuan hukum dalam dimensi global, dalam lingkup hukum internasional yang berkaitan dengan GCG dan Non Discrimination Principles dapat dicermati diantaranya dari OECD (Organization for Economic Cooperation \& Development) dan WTO Agreement (World Trade Organization

Teddy Reinier Sondakh, 2009, Implementasi Prinsip Transparansi Dalam Praktek Penanaman Modal di Indonesia, Bayumedia Publishing, Malang, hlm.11. 
Agreement) dengan salah satu Annex-nya seperti TRIMs Agreement (Agreement on Trade Related Investment Measures). Keterbukaan serta perlakuan yang sama merupakan unsur-unsur penting dari 6 unsur GCG dalam kontek pengaturan $\mathrm{OECD}^{5}$ juga prinsip perlakuan yang sama dalam WTO-TRIMs Agreement khususnya prinsip NT (National Treatment ) tertuang dalam Pasal 2 TRIMs Agreement. ${ }^{6}$

Indonesia sebagai negara bedaulat yang telah mengikuti berbagai perjanjian internasional, termasuk di dalamnya WTO-TRIMs Agreement sudah sepatutnya melaksanakan kewajiban-kewajiban yang telah disepakatinya seperti misalnya kewajiban melaksanakan Prinsip NT yang tertuang dalam Article 2 TRIMs. Mengadopsi serta menjabarkan prinsip-prinsip hukum yang tertuang dalam ketentuan hukum internasional ke dalam tatanan hukum nasional tidaklah semudah membalik tangan, karena dalam realitanya berbagai benturan nilai-nilai yang berbeda serta situasi dan kondisi untuk menyamaratakan suatu negara maju dengan negara berkembang masih sering diperdebatkan dalam studistudi terdahulu yang memfokuskan

Iswandi \& Widya Rahmawati, 2011, Evaluasi Pelaksanaan Penerapan Prinsip Dalam Pengelolaan Perusahaan Yang Baik (Good Corporate Governance) Pada PT Aneka Tambang Tbk, Binus Business Review, Vo. 2 No. 1, Mei 2011, hlm.586-588. Lihat pula Penerapan Prinsip-Prinsip OECD 2004 dalam Peraturan Bapepam mengenai Corporate Governance, Badan Pengawas Pasar Modal Departemen Keuangan Republik Indonesia, http://www.bapepam.go.id/ pasar_modal/publikasi_pm_kajian_pm/studi_2006/ Studi-Penerapan -OECD, hlm.15.

6 TRIMs Agreement, https://www.wto.org/english/ docs_e/legal_e/18-trims.pdf, diakses tanggal 24 Oktober 2015. studinya dalam bidang transplantasi hukum. Meskipun masih banyak persoalan-persoalan dalam kajian tentang transformasi hukum, namun Indonesia sebagai subyek hukum internasional sangat penting mentaati hukum internasional. Vienna Convention on the Law of Treaties 1969, mengamanahkan setiap negara anggota dalam suatu perjanjian internasional wajib mentaati perjanjian internasional yang telah ditandatanganinya.

Dalam kerangka kewajiban Vienna Convention, maka menjadi penting untuk dilakukan penelitian tentang transformasi standar internasional dari suatu perjanjian internasional ke dalam hukum nasional, dalam konteks ini khususnya berkaitan dengan apakah non discrimination system dalam WTO-TRIMs Agreement sudah terjabarkan dalamketentuan hukum berkaitan dengan investasi di Indonesia, begitu juga penjabaran prinsip $G C G$ sebagaimana diatur dalam $O E C D$ ke dalam hukum investasi di Indonesia.

\subsection{Permasalahan}

Fokus kajian dalam tulisan ini membahas permasalahan sebagai berikut:

1. Apakah substansi prinsip non discrimination dalam WTO-TRIMs Agreement serta prinsip-prinsip $G C G$ dalam $O E C D$ dijabarkan dalam ketentuan hukum perusahaan khususnya hukum investasi di Indonesia?

2. Apakah pengecualian dimungkinkan terkait penjabaran prinsip-prinsip TRIMs ke dalam hukum nasional suatu negara anggota termasuk didalamnya Indonesia? 


\subsection{Tujuan Penelitian}

Secara khusus, tulisan ini bertujuan untuk menganalisis penjabaran standar internasional WTO-TRIMs Agreement dan $O E C D$ ke dalam tatanan hukum investasi di Indonesia serta mengkaji pengecualian terhadap prinsip non discrimination yang diwajibkan dalam TRIMs pada level nasional negara anggota.

\section{METODE PENELITIAN}

Metode yang digunakan dalam penelitian ini adalah metode penelitian hukum normatif, dengan pendekatan statute approach, comparative approach, serta conceptual approach dengan meneliti bahan-bahan hukum : WTO Agreement, TRIMs Agreement, OECD, U.U. No. 25 Tahun 2007 Tentang Penanaman Modal, serta U.U. No. 40 Tahun 2007 Tentang Perseroan Terbatas. Bahan hukum dalam penulisan ini, baik primer maupun sekunder dianalisis secara deskriptif kualitatif.

\section{HASIL DAN PEMBAHASAN}

3.1. Prinsip Non Discrimination Dalam WTO-TRIMs Agreement

Dalam studi studi tentang era perdagangan bebas-liberalisasi yang salah satu fondasi utamanya adalah Non Discrimination Principle, dimana World Trade Organization (WTO) seringkali dianggap sebagai instrumen hukum internasional dalam bidang perdagangan yang paling gigih memperjuangkan libralisasi ekonomi dalam pasar dunia, acapkali masih sering diperdebatkan terutama oleh kelompok Negara-Negara Berkembang yang merasa tidak selalu diuntungkan dengan kehadiran fenomena librarisasi ekonomi dan pasar bebasnya dengan piranti hukumnya yang tercakup dalam WTO Agreement . Kegalauan seperti itu juga dipertanyakan oleh Peter Van Den Bossche, sebagaimana ditulisnya: Economic globalization: a blessing or a curse? $^{7}$

Era globalisasi adalah sebuah keniscayaan, yang telah hadir di era ini, setuju atau tidak setuju, fenomena ini telah ada dan tidak bisa dihindari, itu artinya peradaban manusia terus melangkah dan bergerak berproses seiring dengan berprosesnya globalisasi dengan pasar bebasnya yang telah banyak menghasilkan argumen pro dan kontra terutama dalam konteks keberadaan negara berkembang dalam situasi pasar bebas oleh para penstudi terdahulu.

Sebagai sebuah keniscayaan yang tidak bisa dihindari, maka secara bijaksana dapat difahami akan pentingnya hadir kebijakankebijakan atau aturan hukum yang berkaitan dengan perdagangan yang cakupannya internasional. Tanpa eksisnya instrumen hukum perdagangan internasional, baik yang mengikatnegara-negaramaju(richcountries) maupun negara-negara miskin (poor countries), serta pengecualian-pengecualian sebagai bentuk kepedulian terhadap special needs bagi negara-negara berkembang, tentu negara-negara berkembang tidak akan bisa terintegrasi secara penuh dalam perdagangan bebas.

Sehubungan dengan mengapa penting ada ketentuan yang mengatur perdagangan secara internasional, Peter Van Den Bossche mengemukakan sedikitnya ada empat (4)

Peter Van Den Bossche, 2008, The Law and Policy of the World Trade Organization Text, Cases and Materials, CambridgeUniversity Press, UK, p. 9. 
alasan yaitu: 1) Countries must be restrained from adopting trade-restrictive measures both in their own interest and in that of the world economy; 2) The need of traders and investors for a degree of security and predictability; 3) National government alone simply cannot cope with the challenges presented by economic globalization; 4). The need to a chieve agreater measure of equity in international economic relations. ${ }^{8}$

The WTO Law atau yang dikenal dengan sebutan WTO Agreement adalah perjanjian internasional tentang perdagangan sedunia yang sangat komplek dan komprehensif terdiri dari tiga (3) Annexes / Lampiran yaitu: TRIPs Agreement, GATs Agreement dan TRIMs Agreemen. Dalam WTO Agreement pada dasarnya terjabarkan prinsip-prinsip seperti : the principles of non-discrimination, the rules on market access, the rules on unfair trade, the rules on conflict between trade libralsation and other societal values and interests including the rules on special and differential treatment for developing countries, and the rules promoting harmonization of national regulation in specific fields. ${ }^{9}$

Berdasarkan studi terdahulu yang dilakukan oleh Peter Van Deen Bossche tampakjelasbahwaprinsipnondiscrimination merupakan salah satu pilar utama dari konstruksi hukum WTO. Pengejawantahan dari Prinsip Non Discrimination eksis dalam sebutan Prinsip Most-Favoured Nation Treatment (MFN) dan Prinsip National

Ibid, p. 33-35.

Ibid, p. 37. Lihat pula WTO, 2015, Understanding The Wto: Basics Principles of the trading system, https:// www.wto.org/english/thewto_e/whatis_e/tif_e/fact2 e.htm.
Treatment (NT). Prinsip Non Discrimination ini sesungguhnya mengakar pada General Agreement on Tariffs and Trade (GATT 1994). Secara singkat dapat dikemukakan bahwa Non Discrimination Principles melarang adanya perlakuan yang membedamedakan antara satu negara anggota dengan negara anggota lainnya. ${ }^{10}$

Dalam TRIMs Agreement kewajiban bagi negara anggota untuk melaksanakan Prinsip Non Discrimination tertuang dalam Article 2 yaitu yang mengatur tentang National Treatment and Quantitative Restrictions yang harus harmoni dan konsisten dengan Article GATT III atau Article XI of GATT 1994. Dalam kaitannya dengan kegiatan investasi dan perdagangan diatur bahwa tidak boleh ada diskriminasi berkaitan dengan produk-produk asing yang perlakuannya berbeda dengan produk domestik. ${ }^{11}$

Peter Van Den Bossche mengemukakan dari hasil studinya terdahulu bahwa pada intinya ada 5 group prinsip-prinsip dalam WTO Agreement yaitu : non discrimination, market access, unfair trade, rule on conflict between trade libralisation and societal values and sepecial treatment for developing countries, and rule promoting harmonization of national regulation in specific field.

Kelima prinsip dasar tersebut kemudian dalam perkembangannya juga sering dikenal dengan sebutan :

10 Ni Ketut Supasti Dharmawan \& Wayan Wiryawan, 2014, Keberadaan Dan Implikasi Prinsip MFN Dan NTDalam Pengaturan Hak Kekayaan Intelektual Di Indonesia, Jurnal Magister Hukum Udayana, Vo. 3 No. 2 , ISSN : 2302-528X, hlm.260.

11 WTO, 2015, Trade And Investment: Technical Informationn Agreement on Trade Related Investment Measures,https://www.wto.org/english/tratop_e/ invest_e/invest_info_e.htm. 
a. Non Discrimination Principles terdiri dari Prinsip Most Favoured Nations (MFN) dan National Treatment (NT). Dalam perdagangan bebas di era global sekarang ini tidak boleh ada diskriminasi.Tidak boleh ada suatu perlakuan yang lebih istimewa pada satu anggota WTO tertentu dari suatu negara anggota lainnya. Dengan kata lain para anggota WTO Agreement tidak boleh membeda-bedakan, tidak boleh memberikan kemudahan hanya kepada satu negara tertentu saja terhadap tindakanyang berkenaan dengan dan perdagangan. Ketentuan tersebut tertuang Agreement Establising the World Trade Organization yang sumbernya dari Article I (1) jo Article III(2) (4) GATT 1994. Prinsip National Treatment pada intinya menegaskan bahwanegaraanggotaWTO tidakboleh memberikan perlakuan yang berbeda dan diistimewakan antara warga negara domestik atau nasional yang menjalankan kegiatan bisnis dengan warga negara anggota WTO lainnya atau pelaku bisnis non domestik. Prinsip MFN dan NT tertuang dalam lampiran WTO yaitu TRIPS dan GATS, sementara itu yang berkaitan langsung dengan kegiatan investasi yaitu TRIMs hanya mencantumkan Prinsip National Treatment (NT) dalam Article 2 TRIMs.

b. Principles on market Access terdiri dari empat (4) ketentuan hukum yang mendasar yaitu: rule on customs duties, rules on other duties and financial charges, rules on quantitative restrictions, and rules on other "non- tariff barriers. ${ }^{12}$ Khusus untuk prinsip Non-Tariff Measures dimaksudkan bahwa Negara-negara anggota WTO yang melindungi industry dalam negeri sedapat mungkin mengusahakan agar menghindari perlindungan yang bersifat Non-Tariff-measures. Dalam konteks ini transparansi memegang peran penting. Peter Van den Boosche kembali menekankan bahwa Transparency and the fair application of trade regulations are therefore part of the basic rules on market access. ${ }^{13}$

c. Transparency

d. Quantitative Restriction atau Quotas.

\subsection{Penormaan Prinsip TRIMs Non Discrimination Dalam berbagai Hukum terkait Kegiatan Investasi Di Indonesia}

Secara eksplisit ketentuan hukum yang mengatur kegiatan investasi di Indonesia terkonstruksi melalui ketentuan Undang-Undang No 25 Tahun 2007 Tentang Penanaman Modal. Dalam kaitannya dengan kegiatan penanaman modal atau investasi, dalam level internasional khususnya dalam TRIMs hanya mengakomodir 3 prinsiputama dari 5 prinsip yang ada dalam WTO yaitu :National Treatment, Quantitative Restriction dan Transparancy. Oleh karena itu sekurang-kurangnya di tingkat domestik suatu negara anggota wajib untuk menjabarkan ketentuan internasional tersebut sebagai bentuk kepatuhan terhadap kewajiban internasional.

\footnotetext{
12 Peter van Deen Boosche, Op.Cit, p.39.

13 Peter van Deen Booshe, Op.Cit, p. 40.
} 
TRIMs Agreement yang dikenal sebagai salah satu Annex dari WTO dalam konsiderannya secara tegas mengatur bahwa tujuan dari perjanjian internasional ini adalah untuk mempromosikan pengembangan libralisasi perdagangan dunia secara progresif dengan maksud memfasilitasi perkembangan investasi lintas negara secara internasional dalam kerangka meningkatkan pertumbuhan perekonomian dari semua pihak, khususnya parther-parther pedagang / investor dari anggota negara-negara berkembang dengan tetap mengedepankan persaingan bebas dalam perdagangan yang berbasis prinsip-prinsip WTO-TRIMs Agreement. Perjanjian internasional ini juga menekankan bahwa ruang lingkupnya hanya mencakup perdagangan barang saja. Perdagangan jasa secara sepesifik diatur melalui General Agreement Trade Services (GATS).

Prinsip National Treatment dan Quantitative Restrictions tertuang dalam Article 2 of TRIMs sebagai berikut:

1. Without prejudice to other rights and obligations under GATT 1994 no Member shall apply any TRIM that is inconsistent with the provisions of Article III or Article XI of GATT 1994.

2. An illustrative list of TRIMs that are inconsistent with the obligation of national treatment provided for in paragraph 4 of Article III of GATT 1994 and the obligation of general elimination of quantitative restrictions provided for in paragraph 1 of Article XI of GATT 1994 is contained in the Annex to this Agreement
Berdasarkan ketentuan Article 2 dari Agreement on Trade-Related Investment Measures (TRIMs) seperti tersebut di atas, dengan mengacu pada ketentuan Article III dan Article XI GATT 1994 prihal National Principles, pada intinya dapat dikemukakan bahwa dalam kegiatan investasi tidak boleh ada diskriminasi perlakuan terhadap produk-produk barang import dari Negara anggota lainnya. Dengan kata lain, melarang memperlakukan produk-produk perdagangan dari Negara anggota WTO lebih rendah perlakuannya dari produk domistik. Melalui ketentuan Article 2 TRIMs secara tegas tampak pengejawantahan dari Non Discrimination Principles. Jurgen Kurtz dalam studinya terdahulu mengemukakan bahwa pengaturan National Treatment Principles eksis dalam bagianbagian pengaturan dari WTO termasuk dalam GATT dan GATs. Berdasarkan Article III GATT diatur tentang kewajiban Negara anggota WTO untuk menjalankan kewajiban berkaitan dengan Prinsip National Treatment yaitu perlakuan yang sama bagi produk barang import. Dengan kata lain (no less favourable that that accorded to like products of national origin in respect of all laws). ${ }^{14}$

Dalam hukum investasi di Indonesia, Prinsip National Treatment terkonstruksi melalui ketentuan Pasal 3, Pasal 4 dan Pasal 6 Undang-Undang No. 25 Tahun 2007 Tentang Penanaman Modal (UUPM). Berdasarkan ketentuan Pasal 3 UUPM

14 Jürgen Kurtz , 2009, The Use and Abuse of WTO Law in Investor-State Arbitration: Competition and its Discontentss, The European Journal of International Law Vol.20 no. 3, EJIL 2009, http://ejil.oxfordjournals. org/content/20/3/749.full.pdf+html, p. 753. 
dapat diketahui bahwa salah satu asas yang melandasi kegiatan penanaman modal di Indonesia adalah asas perlakuan yang sama dan tidak membedakan asal negara. Melalui ketentuan Pasal 4 (2) huruf a. UUPM dapat difahami bahwa pemerintah Indonesia memberi perlakuan yang sama bagi penanam nodal dalam negeri dan penanam modal asing melalui kebijakan dasar penanaman modal di Indonesia. Namun demikian ketentuan pasal ini juga menekankan bahwa perlakuan yang sama dengan tetap memperhatikan kepentingan nasional. Lebih lanjut penjabaran Prinsip Non Discrimination dapat dicermati dari ketentuan Pasal 6 (1) U.U. No. 25 Tahun 2007 yang menentukan bahwa Pemerintah memberikan perlakuan yang sama kepada semua penanam modal yang berasal dari Negara manapun yang melakukan kegiatan penanaman modal di Indonesia sesuai dengan ketentuan peraturan perundang-undangan.

Penjabaran prinsip Non Discrimination dalam UUPM di Indonesia tampak tidak sepenuhnya konsisten dengan TRIMs. Seperti misalnya sebagaimana tertuang dalam Pasal 4 (2) huruf. a. UUPM diatur tentang perlakuan yang sama, namun tetap memperhatikan kepentingan nasional. Realita penormaan substansi hukum seperti itu bukanlah menyiratkan bahwa Indonesia sebagai salah satu Negara anggota telah tidak comply atau tidak patuh dengan kewajibankewajiban WTO, karena sesungguhnya dalam ketentuan hukum WTO termasuk juga dalam TRIMs Agreement diberi ruang atau mengatur pengecualian, yaitu special need for developing country members.

Prinsip Transparency yang tertuang dalam Article 6 TRIMs eksis penjabarannya dalam hukum investasi Indonesia yaitu melalui Pasal 3 UUPM. H Salim dan Budi Sutrisno mengemukakan ada 10 asas yang melandasi kegiatan penanaman modal atau investasi di Indonesia, salah satunya adalah asas keterbukaan, yaitu asas yang terbuka terhadap hak masyarakat untuk memperoleh informasi yang benar, jujur, dan tidak diskriminatif tentang kegiatan penanaman modal. ${ }^{15}$ Prinsip Transparansi dalam TRIMs bersumber dari GATT 1947 Article $X$ berkaitan dengan Publication and Administration of Trade Regulations.

\subsection{Prinsip Good Gorporate Governance (GCG) Dalam OECD 2004}

Keberhasilan suatu kegiatan investasi sangat ditentukan oleh konsistensi semua pihak menerapkan prinsip Good Corporate Governance (GCG. Organization for Economic Cooperation and Development (OECD) yang didirikan pada tahun 1948 dengan dimotori oleh negara-negara maju dan kaya seperti Amerika Serikat dan Eropa, adalah salah satu organisasi internasional yang sangat fokus memperjuangkan pengimplementaian prinsip GCG dalam suatu perusahaan. OECD bertujuan untuk meningkatkan kerjasama ekonomi dan pembangunan, khususnyabaginegara-negara berkembang yang setuju dan bersama-sama menerapkan Good Corporate Governance $(G C G)$ dalam tatanan pasar ekonomi global.

Dalam rangka pasar global, negaranegara anggota $O E C D$ secara terusmenerus berkomitmen menjalankan

H. Salim HS \& Budi Sutrisno, 2012, Hukum Investasi Di Indonesia, PT Raja Grafindo Persada, Jakarta, hlm.14-15. 
kewajibannya dalam rangka liberalisasi, serta menggunakan upaya terbaiknya dalam memperluas manfaat dari proses libralisasi bagi seluruh negara-negara anggotanya untuk memastikan kegiatan investasi internasional dapat berlangsung tanpa hambatan dan transparan.

Berkaitan dengan investasi internasional dan keberadaan perusahaan multinasional di dalamnya, OECD telah mengeluarkan Deklarasi (1976) kemudian dilakukan Review Deklarasi (1991) yang dibuat dan diikuti oleh Negara-negara anggota $O E C D$ maupun non anggota negaranegara lainnya yang sedang dipertimbangkan untuk bergabung dalam $O E C D$. Review utama dari Deklarasi $O E C D$ selesai pada tahun 2000. Dalam Deklarasi tersebut mengatur 4 (empat) unsur penting yaitu: 1).Pedoman untuk Perusahaan Multinasional agar memperhatikan dan menerapkan etika bisnis, lapangan kerja dan hubungan industrial, Hak Asasi Manusia, lingkungan, keterbukaan informasi, memerangi penyuapan kepentingan konsumen, serta persaingan usaha sehat dan perpajakan; 2).Melaksanakan Prinsip National Treatment ; 3).Anggota harus bekerjasama untuk menghindari persyaratan yang saling bertentangan dan mengedepankan pendekatan konsultasi; serta 4).Insentif dan diinsentif investasi internasional.

$O E C D$ mengatur berbagai kegiatan berkaitandengan ekonomibebas(liberalisasi) khususnya investasi internasional serta bidang jasa seperti : perbankan dan jasa keuangan, asuransi, transportasi, travel, dan pariwista. Dalam berbagai kegiatan usaha seperti tersebut, OECD mengatur agar dalam menjalankan kegiatan usahanya
Perusahaan-perusahaan menerapkan Prinsip $G C G$ atau yang di Indonesia sering dikenal dengan istilah Prinsip Tata kelola Perusahaan Yang Baik. Berdasarkan OECD 2004 terdapat enam (6) elemen penerapan $G C G$ yaitu: ${ }^{16}$ Ensuring the Basis for an Effective Corporate Governance Framework, The Rights of Shareholders and Key Ownership Functions, The Equitable Treatment of Shareholders, The Role of Stakeholders in Corporate Governance, Disclosure and Transparency, serta The Responsibilities of the Board.

Berdasarkan 6 elemen GCG serta DeklarasiOECD2004, dapatdicermatibahwa prinsip-prinsip yang dikedepankan oleh OECD sebagai aturan hukum bagi negaranegara anggotanya juga diperuntukkan bagi negara berkembang dalam kegiatan pasar bebas adalah selain prinsip-prinsip GCG juga prinsip Non Discrimination, khususnya National Treatment (NT) yang menekankan bahwa perlakuan yang sama antara perusahaan asing dan perusahaan domestik atau memperlakukan perusahaan asing tidak kurang menguntungkan dari perusahaan domestic dalam suatu situasi yang sama. Namun demikian pemberlakuan prinsip $N T$ dalam hal ini juga memperhatikan pengecualian-pengecualian seperti misalnya dalam kerangka akses bagi kredit lokal perbankan dan pasar modal.

\footnotetext{
16 Tim Studi Pengkajian, 2006, Penerapan PrinsipPrinsip OECD 2004 dalam Peraturan Bapepam Mengenai Corporate Governance, Departemen Keuangan RI, Badan Pengawas Pasar Modal dan Lembaga Keuangan, Jakarta, hlm.12-86.
} 
3.4 Penjabaran Prinsip-Prinsip OECD Dalam Ketentuan Hukum Terkait Kegiatan Investasi Di Indonesia

Kegiatan investasi dibedakan menjadi kegiatan investasi tidak langsung dan kegiatan investasi langsung. Kegiatan Investasi tidak langsung berkaitan dengan kegiatan portofolia atau kegiatan investasi di pasar modal yang mana pemegang sahamnya atau sering dikenal dengan investor publik bersifat pasif, dengan kata lain tidak melakukan pengelolaan secara aktif atas saham-sahamnya. Sementara itu dalam investasi langsung, para investornya melakukan kegiatan usaha serta mengelola perusahaan secara langsung. Para investor dalam konteks ini berkeddudukan aktif. Dalam perkembangan global karena investasi langsung dominan bersentuhan dengan investor asing, maka acapkali kegiatan investasi langsung juga dikenal dengan sebutan Foreign Direct Investment (FDI). OECD mendifinisikan FDI sebagai kegiatan investasi lintas batas (cross border), dimana suatu entitas bertujuan untuk membangun suatu perusahaan yang motivasinya bertujuan secara langsung mengelola, mengerahkan pengaruh pengelolaan secara langsung atas perusahaan investasinya. Investor secara signifikan mengontrol, mengendalikan dan berpengaruh terhadap jalannya suatu perusahaan. ${ }^{17}$

\section{Menurut OECD, keberadaan} FDI memberikan dampak positif bagi Negara tuan rumah (Host Country) seperti misalnya memberikan kontribusi integrasi perdagangan internasional, meningkatkan perkembangan teknologi, pertumbuhan ekonomi, berkontribusi mengurangi kondisi kemiskinan bagi Negara-negara berkembang, meningkatkan kondisi sosial dan lingkungan, serta diantara keuntungan yang bersifat ekonomi, FDI berkontribusi seperti misalnya "transferring "cleaner" technology and leading to more socially responsible corporate policies ${ }^{18}$. Persoalanpersoalan yang berkaitan dengan Corporate Social Responsibility (CSR) menjadi mendapat perhatian dalam konteks investasi ini, FDI mampu meningkatkan pengaturan kebijakan korporasi yang lebih bertanggungjawab.

Indonesia sesungguhnya bukanlah negara anggota dari Konvensi OECD, keanggotaan OECD secara umum terdiri dari Negara-Negara kaya dari Eropa dan Amerika Serikat ${ }^{19}$. Namun demikian, sejak tahun 2007 Indonesia menjadi mitra utama OECD, berbagai kerjasma bilateral yang saling menguntungkan telah dijalin. Pada tahun 2012 kemitraan antara Indonesia dengan OECD diresmikan melalui Perjanjian Kerangka Kerjasama (Framework of Cooperation Agreement) yang berfungsi unuk memfasilitasi keikutsertaan Indonesia dalam serangkaian proyek OECD. ${ }^{20}$

18 OECD, 2002, Foreign Direct Investment for Development"Maximizing Benefits, Minimazing Cost, http://www.oecd.org/investment/ investmentfordevelopment/1959815.pdf, p.5.

19 Negara anggota OECD terdiri dari : Australia, Austria, Belgium, Canada, Chile, Czech Republic, Denmark, Estonia, Finland, , France, Greece, Hungary, Ireland, Israel, Italy, Luxenburg, Mexico, Japan, Newzealnd, Norwey, United Kingdom, dan United America (Amerika Serikat). Lihat OECD 2015, List of OECD member Countries Ratification of the Convention on the OECD, http://www.oecd.org/about/ membersandpartners/list-oecd-member-countries. htm, p.1.

20 OECD 2015, Indonesia dan OECD: Kemitraan yang Saling Menguntungkan, http://www.oecd.org/ globalrelations/keypartners/Indonesia\%20brochure \% 20Bah_web.pdf, hlm.2. 
Kemitraan antara OECD dan Indonesiaberkaitan dengan kegiataninvestasi dikuatkan melalui suatu kebijakan investasi yang dikenal dengan sebutan Investment Policy Review. Tujuan dari kebijakan investasi ini adalah untuk lebih menarik baik investor dalam negeri maupun investor asing dalam kegiatan investasi. Lebih khusus lagi berkaitan dengan peningkatan mutu kegiatan dunia usaha di Indonesia juga telah dilakukan dan dirumuskan prinsipprinsip yangberkaitan dengan Corporate Governance dalam suatu dialog yang dikenal dengan sebutan "Indonesia-OECD Policy dialogue on Corporate Governance”.

Dalam konteks Indonesia, prinsipprinsip Good Corporate Governance dijabarkan sebagai berikut:

1. Perlindungan atas hak-hak pemegang saham , perlindungan yang sama fairness.

2. Perlindungan atas hak-hak pemegang saham

3. Perlakuan yng adil bagi seluruh pemegang saham.

4. Peranan stakeholder dalam corporate governance

5. Keterbukaan dan transfaransi

6. Akuntabilitas Direksi dan Komisaris.

Prinsip Good Corporate Governance telah dijabarkan dalam berbagai ketentuan hukum yang berkaitan dengan kegiatn investasi atau kegiatan perusahaan. Diantaranya dalam U.U. No. 40 Tahun 2007 tentang Perseroan Terbatas (UUPT), prinsip fairness, pemberian hak yang sama secara tanpa adanya diskriminasi perlakuan kepada pemegang saham untuk klasifikasi saham yang sama. Ketentuan tersebut tertuang dalam Pasal 53 Ayat 2 UUPT. Lebih lanjut prinsip Transparansi tertuang dalam ketentuan Pasal Pasal 44 Ayat 2 UUPT, Pasal 50 Ayat 2, Pasal 101 ayat 1 dan Pasal 116 UUPT. Prinsip Akuntabilitas tertuang dalam Pasal 108 Ayat 1, serta prinsip Responsibility diatur dalam Pasal 97 Ayat 4 UUPT, Pasal 114 Ayat 4 dan Pasal 152 Ayat 1 UUPT.

Prinsip GCG juga dituagkan dengan sangat rinci pada berbagai ketentuan berkaitan dengan sektor keuangan dan perbankan seperti : PBI nomor 8/14/ PBI/2006 menyebutkan bahwa setiap bank wajib menerapkan $G C G$. Juga dalam peraturan OJK diatur tentang $G C G$.

\subsection{Pengecualian Prinsip-Prinsip TRIMS Dalam Konteks Harmonisasi dan Mekanisme Kontrol Kepatuhan Indonesia Sebagai Negara Anggota WTO}

Pada uraian sebelumnya telah dikemukakan bahwa Indonesia dalam mengembangkan kegiatan investasi dalam tatanan global, pada intinya telah menjabarkan Prinsip-Prinsip $G C G$ dari $O E C D$ meskipun Indonesia bukanlah negara anggota dari Konvensi tersebut. Kepatuhan Indonesia terhadap kebijakankebijakan yang berkaitan dengan tata kelola perusahaan yang baik sebagaimana diatur dalam OECD. Meskipun bukan sebagai negara anggota, Indonesia menyadari peran dan dukungan dari organisasi dunia yang satu ini yang didukung oleh negara-negara maju dirasakan relevan dan sangat berkontribusi positif dalam proses pengembangan kegiatan dunia usaha di bidang investasi terutama dari aspek pertanggungjawaban perusahaan 
dan keterbukaan, yang pada akhirnya dapat meningkatkan citra baik iklim berinvestasi di Indonesia, namun dalam usaha tersebut tidak merusak tatanan dan nilai-nilai yang bertumbuh di Indonesia yang memiliki nilainilai fundamental yang mungkin saja tidak selalu dalam satu koridur dengan nilai-nilai barat.

Berkaitan dengan Prinsip-Prinsip $W T O$, dalam konteks ini prinsip yang terkandung dalam TRIMs Agreement, meskipun Indonesia adalah salah satu negara anggota WTO, dapat dikemukakan bahwa pada umumnya Indonesia telah menjabarkan prinsip-prinsip TRIMs seperti misalnya prinsip National Treatment (NT) sebagai salah satu pilar dari pengejawantahan prinsip Non Discrimination, namun Indonesia juga mengatur pembatasan-pembatasannya. Dengan kata, meskipun tampaknya Indonesia tidak sepenuhnya menjabarkan Prinsip NT, seperti halnya diatur dalam ketentuan Pasal 4 (2) huruf. a. Undang-Undang Penanaman Modal yang pada intinya memberi perlakuan yang sama, namun tetap memperhatikan kepentingan nasional, realita seperti itu bukan berarti Indonesia tidak harmoni dan tidak mengakomodir dengan prinsip-prinsip WTO-TRIMs, akan tetapi harus juga dikaji dari kepentingan dan nilai-nilai yang berbeda yang ada pada suatu negara anggota. Selain itu, jika dicermati perjanjian internasional (WTO Law) itu sendiri memberi ruang bagi negara berkembang dalam koridur "special need for developing countries ", termasuk didalamnya Indonesia. Kiranya pengecualian seperti itu dapat digunakan termasuk Indonesia untuk mengatur "dengan tetap memperhatikan kepentingan nsional" sebagai bentuk perwujudan dari penggunaan sepecial need for developing countries members dalam menyimpangi prinsip non discrimination sebagaimana tertuang dalam Article 2 TRIMs.

Perjanjian TRIMs pada dasarnya mengatur tentang kegiatan-kegiatan investasi serta menyatukan kebijakan yang berkaitan dengan perdagangan investasi asing dari seluruh Negara anggota WTOTRIMs Agreement, serta mencegah proteksi sesuai dengan prinsip-prinsip GATT. Dengan kata lain TRIMs melarang negara anggota mengatur kebijakan penanaman modal asing yang menyimpangi prinsipprinsip GATT 1994. Namun demikian melalui ketentuan Pasal 3 TRIMs, Negara anggota dalam kondisi tertentu, misalnya dalam hal mengalami kesulitan sangat berarti dalam negaranya diperbolehkan melakukan pengecualian-pengecualian terhadap kewajiban -kewajiban TRIMs. Article 3 TRIMs secara lengkap mengatur prihal Exceptions: All exceptions under GATT 1994 shall apply, as appropriate, to the provisions of this Agreement. Lebih lanjut dalam Pasal 4 TRIMs juga ditegaskan kembali pengecualian tersebut bagi Negaranegara anggota dari Negara berkembang Developing Country). Article 4 TRIMs mengatur :

"A developing country Member shall be free to deviate from provisions of Article 2 to the extent and in such a manner as Article XVIII of GATT 1994, the understanding on the balances-of-Payments Provisions of GATT 1994, and the Declaration on Trade Measures Taken for Balance-of-Payments Purposes adopted on 28 November 1979 (BISD 26S/205-209 permit the Member to deviate from the provisions of Articles III and XI of GATT 1994". 
Berkaitandenganpengecualiantersebut di atas, TRIMs lebih lanjut melalui Pasal 5 mengatur agar negara-negara anggota yang belum sepenuhnya melaksanakan kewajiban sebagaimana diatur dalam Article 2 TRIMs yang berkaitan dengan National Treatment (Not conformity) agar menginformasikan kepada Dewan Perdagangan Barang dari TRIMs (shall notify the Council for Trade in Goods of all TRIMs).

Pasal 5 TRIMs ini mengatur, antara lain: (a) setiap negara anggota diberikan waktu 90 (sembilan puluh) hari sejak berlakunya persetujuan WTO harus melakukan notifikasi kepada Council for Trade in Goods mengenai semua TRIMs yang diterapkan dan tidak sejalan dengan TRIMs, baik yang berlaku umum maupun yang berlaku khusus disertai dengan ketentuan yang mengaturnya. Dalam hal TRIMs diterapkan berdasarkan kewenangan yang tidak bersyarat, setiap penerapan spesifik harus diberitahukan. (b) menghapuskan semua TRIMs yang dinotifikasi tersebut dalam waktu 5 (lima) tahun sejak berlakunya persetujuan WTO untuk anggota yang tergolong negara berkembang, dan 7 (tujuh) tahun untuk anggota negara terbelakang. (c) Negara anggota dapat memperpanjang masa peralihan untuk menghapuskan TRIMs dengan mengajukan permohonan ke Council dengan memberikan alasan yang jelas kesulitan yang dihadapi dalam melaksanakan persetujuan TRIMs. ${ }^{21}$

Prinsip-prinsip TRIMs pada intinya wajib dijabarkan dalam ketentuan hukum

21 Orinton Purba, 2010, Perdagangan Global Dan Tindakan Investasi: TRIMs, https://hukuminvestasi. wordpress.com/2010/09/16/trade-related-investmentmeasures-trims/, ph. yang berkaitan dengan kebijakan investasi perdagangan khususnya yang menyangkut penanaman modal asing, namun tetap dimungkinkan untuk melakukan pengecualian-pengecualian sepenjang memenuhi persyaratan tertentu. Dalam konteks ketentuan Pasal 4 Ayat (2) a UUPM tentang pengecualianyang dilakukan Indonesia atas tidak sepenuhnya kewajiban terhadap Prinsip National Treatment dilaksanakannya seyogyanya difahami masih dalam koridor pengecualian yang dimungkinkan berdasarkan ketentuan Pasal 3 sampai dengan 5 TRIMs. Dalam kerangka WTO pengecualian terhadap prinsip NT juga datur berkaitan dengan persyaratan procurement untuk pemerintah. The national treatment provisions do not apply, however, to laws, regulations or requirements governing the procurement of goods by government agencies for governmental use.... This agreement was revised further under the Uruguay Round. The revised version came into force on January 1, $1996 .^{22}$

\section{IV . PENUTUP}

\subsection{Simpulan}

Berdasarkan uraian pada Bab-Bab sebelumnya dapat disimpulkan sebagai berikut:

1. Indonesia sebagai salah satu negara anggota WTO-TRIMs Agreement telah menjabarkan Prinsip Non Discrimination khususnya prinsip National Treatment (NT) dan prinsip Transparancy ke dalam Undang-

\footnotetext{
22 Arvind Panagariya, Core WTO Agreements: Trade in Goods and Services and Intellectual Property, www. columbia.edu/ ap2231/.../wto-overview.do..., p.31.
} 
Undang Pasar Modal Indonesia melalui ketentuan Pasal 3, Pasal 4 dan Pasal 6 Undang-Undang No. 25 tahun 2007 Tentang Pasar Modal. Sementara itu meskipun Indonesia bukan sebagai Negara anggota OECD namun sebagai mitra kerja telah menjabarkan enam (6) Prinsip-prinsip utama dari OECD khususnya yang berkaitan dengan $G C G$ ke dalam berbagai ketentuan perundang-undangan yang berkaitan dengan perdagangan barang dan jasa seperti dalam Undang-Undang No. 40 Tahun 2007 Tentang Perseroan Terbatas, PBI Nomor 8/14/PBI/2006, serta peraturan OJK.

2. Dalam kerangka perjanjian internasional WTO-TRIMs Agreement pada dasarnya setiap negara anggota berkewajiban mentaati prinsip-prinsip TRIMs yang telah disepakatinya. Namun demikian dalam kerangka harmonisasi hukum baik berkaitan dengan kesulitan-kesulitan terkait kondisi sosial, ekonomi, serta nilai-nilai yang mungkin berbeda di suatu negara anggota termasuk Indonesia, WTOTRIMs memberikan pengecualianpengecualian dengan persyaratan wajib menotifikasikan kepada Dewan TRIMs. Dalam kerangka kewajiban Indonesia menjabarkan prinsip Non Discrimination dalam ketentua investasi (UUPM) tampak tidak sepenuhnya konsisten dengan TRIMs. Sebagaimana dalam Pasal 4 (2) huruf. a. UUPM mengatur tentang perlakuan yang sama, namun tetap memperhatikan kepentingan nasional. Realita penormaan substansi hukum seperti itu bukanlah menyiratkan bahwa Indonesia sebagai salah satu negara anggota yang tidak patuh dengan kewajiban-kewajiban WTO, karena sesungguhnya dalam ketentuan hukum WTO termasuk juga dalam TRIMs Agreement diberi ruang atau mengatur pengecualian yaitu special need for developing country members sebagaimana diatur dalam Pasal 3 sampai dengan Pasal 5 TRIMs.

\subsection{Saran}

1. Dalamrangkakewajibannegaraanggota terhadap perjanjian internasional yang telah disepakatinya seperti halnya terhadap TRIMs Agreement, diharapkan Indonesia mengatur secara lebih rinci tentang penjelasan penyimpangan / pengecualian terhadap kebijakan TRIMs sebagaimana sekarang di Indonesia eksis melalui ketentuan Pasal 4 ayat 2 (b) U.U. No. 25 Tahun 2007 tentang Pasar Modal.

2. Diharapkan penyimpanganpenyimpangan terhadap prinsipprinsip internasional yang telah disepakati dijabarkan juga secara lebih detail melalui Country Report yang dilaporkan secara periodik oleh setiap negara anggota termasuk Indonesia dalam kerangka kepatuhan terhadap kewajiban TRIMs Agreement.

\section{DAFTAR PUSTAKA \\ BUKU}

Bambang Sunggono. 2001. Metodologi Penelitian Hukum. PT RajaGrafindo Persada. Jakarta.

Huala Adolf. 2004. Perjanjian Penanaman 
Modal dalam Hukum Perdagangan Internasional (WTO). PT Raja Grafindo Persada. Jakarta.

H. Salim HS \& Budi Sutrisno, 2012, Hukum Investasi Di Indonesia, PT Raja Grafindo Persada, Jakarta

Iswandi \& Widya Rahmawati, 2011,Evaluasi Pelaksanaan Penerapan Prinsip Dalam pengelolaan Perusahaan Yang Baik (Good Corporate Governance) Pada PT Aneka Tambang Tbk, Binus Business Review, Vo. 2 No. 1, Mei 2011.

Johnny Ibrahim. 2007. Teori \& Metodologi Penelitian Hukum Normatif. Bayumedia Publishing. Malang.

Peter Van Den Bossche, 2008, The Law and Policy of the World Trade Organization Text, Cases and Materials, CambridgeUniversity Press, UK.

Soerjono Soekanto dan Sri Mamudji. 2007. Penelitian Hukum Normatif: Suatu Tinjauan Singkat. PT Raja Grafindo Persada. Jakarta.

Teddy Reinier Sondakh, 2009, Implementasi

Prinsip Transparansi Dalam Praktek Penanaman Modal di Indonesia, Bayumedia Publishing, Malang

\section{INTERNET}

Jürgen Kurtz, 2009, The Use and Abuse of WTO Law in Investor-State Arbitration: Competition and its Discontentss, The European Journal of International Law Vol. 20 no. 3 , EJIL 2009, http://ejil. oxfordjournals.org/content/20/3/749.full. pdf + html.

Ni Ketut Supasti Dharmawan \& Wayan Wiryawan, 2014, Keberadaan Dan Implikasi Prinsip MFN Dan NT Dalam Pengaturan
Hak Kekayaan Intelektual Di Indonesia, Jurnal Magister Hukum Udayana, Vo. 3 No. 2 , ISSN : 2302-528X,http://ojs.unud.ac.id/ index.php/jmhu.

OECD, 2008, OECD Benchmark Definitian of Foreign Direct Investmen, h t t p : / / w w w o e c d . org / d a f/i n v / investmentstatisticsandanalysis/40193734. pdf.

OECD, 2002, Foreign Direct Investment for Development"Maximizing Benefits, Minimazing Cost, http://www.oecd. org/investment/investmentfordevelopment/ 1959815.pdf

OECD 2015, List of OECD member Countries Ratification of the Convention on the OECD, http://www.oecd.org/about/ membersandpartners/list-oecd-membercountries.htm.

OECD 2015, Indonesia dan OECD: Kemitraan yang Saling Menguntungkan, http://www.oecd.org/globalrelations/ keypartners/Indonesia\%20Bah_web.pdf.

Tim Studi Pengkajian Bapepam, 2006, Penerapan Prinsip-Prinsip OECD 2004 dalam Peraturan Bapepam mengenai Corporate Governance, Badan Pengawas Pasar Modal Departemen Keuangan Republik Indonesia ,http://www.bapepam. go.id/pasar_modal/publikasi_pm_kajian_ $\mathrm{pm} /$ studi_2006/Studi-Penerapan-OECD.

WTO, 2015, Understanding The Wto: Basics Principles of the trading system, http://www.wto.org/english/thewto_e/ whatis_e/tif_e/fact2 e.htm.

WTO, 2015, Trade And Investment: Technical Informationn Agreement on Trade Related Investment Measures,http://www. wto.org/english/tratop_invest_e/invest_ info e.htm. 


\section{PERATURAN}

\section{PERUNDANG-UNDANGAN}

----------, Undang-Undang Penanaman

Modal. UU No. 25 Tahun 2007.

---------, Undang-Undang Perseroan

Terbatas, UU No. 40 Tahun 2007.

, WTO Agreement

, GATT

-, TRIMs Agreement

- , GATs 